\title{
O CODA, FILHOS OUVINTES DE PAIS SURDOS, E A TRADUÇÃO E INTERPRETAÇÃO DE LIBRAS: O QUE ENCONTRAMOS?
}

\author{
THE CODA, CHILDREN OF DEAF ADULTS, AND LIBRAS TRANSLATION AND \\ INTERPRETATION: WHAT DO WE FIND?
}

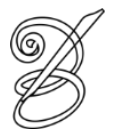 \\ Maitê Maus da SILVA ${ }^{\mathrm{i}}$ \\ Universidade Federal de Pelotas
}

\begin{abstract}
Resumo: Neste artigo será apresentada uma breve revisão bibliográfica de trabalhos acadêmicos que versam sobre a atuação e mediação linguística do Coda - filhos ouvintes de pais surdos, usuários e intérpretes de Libras durante a infância, bem como uma análise teórica dessas produções. Este trabalho tem uma abordagem qualitativa e traz como instrumentos de investigação cinco textos acadêmicos: dois artigos e três dissertações que foram publicadas até o ano de 2016. Trata-se de um recorte da dissertação da proponente deste estudo, que foi publicada em 2016 pelo Programa de Pós-Graduação em Estudos da Tradução da UFSC. Diante do referido estudo, concluímos que as experiências desses sujeitos vão além da escolha pela profissão de Tradutores e Intérpretes de Libras, influenciando, também, as suas produções acadêmicas, compartilhando, além das histórias de vida e escolhas profissionais, os relatos que fortalecem a necessidade de investigação das questões relacionadas ao sujeito Coda e suas vivências.
\end{abstract}

Palavras-chave: Codas. Tradutores Intérpretes. Língua de Sinais. Experiências da Infância.

Abstract: In this article you will be presented with a brief literature review of academic papers that focus on the performance and linguistic mediation of Coda-children of deaf adults, users and interpreters of Libras during childhood, as well as a theoretical analysis of these productions. This paper adopts a qualitative approach and a study of the content, having as research instruments five academic texts, two articles and three dissertations published until the year 2016. This is a clipping of the dissertation of the proponent of this study, which was published in 2016 by the Post-Graduation Program in Translation Studies of the UFSC. In the face of this study, we conclude that the experiences of those subjects are beyond the choice for the profession of translator and interpreter of Libras, influencing, also, their academic productions, sharing, in addition to the life stories and professional choices, the reports that strengthen the need for investigation of issues related to the Coda subject and their experiences.

Keywords: Codas, Translator Interpreters, Sign Language, Childhood Experience.

RECEBIDO EM: 20 de março de 2018

ACEITO EM: 10 de dezembro de 2018

PUBLICADO EM: janeiro 2019 


\section{Introdução}

raremos neste artigo uma revisão bibliográfica analítica com o objetivo de refletir
sobre a descrição dos Codas - Children of Deaf Adults - em textos acadêmicos,
relacionando suas experiências com a tradução e interpretação de Língua Brasileira de Sinais (Libras) e Língua Portuguesa. Este artigo é um recorte da minha dissertação de mestrado, que objetivava apresentar o percurso da experiência e da prática dos sujeitos Codas na profissão de tradutores e intérpretes de Libras.

Inicialmente, é necessário compreendermos a origem do termo a partir da sigla em inglês CODA, que tem como significado a expressão "filhos de pais surdos". Optamos por utilizar a sigla Coda durante o trabalho, pois, no Brasil, não foi criada outra sigla ou palavra específica para nomear esses sujeitos. Sendo assim, mantemos a sigla utilizada nos Estados Unidos da América - EUA como, também, em outros países da América Latina, Europa e Ásia.

O Coda, geralmente, cresce em meio a duas culturas, duas línguas, e no contato com muitas experiências visuais, diferentemente de outras crianças que não são filhas de surdos. As 38 pesquisas acadêmicas em torno de filhos de pais surdos ainda são recentes no Brasil, pois grande parte desses estudos encontram-se na América do Norte e na Europa (SOUZA, 2014, p.35).

A terminologia Coda, conforme já comentamos anteriormente, é de origem estadunidense, sendo também utilizada pela associação que realiza encontros com filhos de pais surdos. No caso da associação, é empregada a sigla $\operatorname{CODA}^{1}$, que é usada com letras maiúsculas para se referir à organização, em contraste com o termo em letras minúsculas, que se refere às pessoas. A CODA foi fundada em 1983 e defende a ideia de que os Codas, em diferentes partes do mundo, vivenciam experiências muito semelhantes, reconhecendo-se como sujeitos biculturais (SOUZA, 2014, p.37-38).

A nosso ver, a necessidade de discutirmos a respeito dos Codas surgiu em função do número de Codas que atuam na área da tradução e interpretação do par linguístico LibrasLíngua Portuguesa. As questões que fomentam o estudo convergem para a relação construída entre o Coda e seus pais e entre o Coda e a comunidade surda ${ }^{2}$.

Buscando observar o que é dito sobre os Codas na literatura acadêmica nacional, selecionamos um corpus composto por cinco textos, sendo estes dois artigos e três dissertações que compartilham experiências da atuação do Coda Tradutor-Intérprete: Masutti (2007), Andrade (2011), Pereira (2014), Souza (2014) e Oliveira (2014). Tratam-se de trabalhos que interpelam a temática Coda de uma forma indireta, além de serem textos acadêmicos 
encontrados por mim e publicados no Brasil até 2016/2. Vale ressaltar que não foram não foram publicadas teses ou dissertações no Brasil, abordando as experiências dos Codas, após a data supracitada.

Essa discussão visa a contribuir para que possamos realizar uma reflexão acerca das experiências de vida e de interpretação durante a infância desses sujeitos, podendo refletir hoje em suas escolhas profissionais como Codas tradutores-intérpretes de Língua Brasileira de Sinais - CTILS (SILVA, 2016).

\section{A Tradução, interpretação e os Codas.}

De acordo com Pagura (2003), a profissão de tradutores e intérpretes datam desde a Antiguidade. Conforme o mesmo autor, na Primeira e Segunda Guerra Mundial a interpretação ganha destaque em razão das muitas nações envolvidas nos conflitos. Por exemplo, com o fim da Segunda Guerra, o conhecido julgamento de Nuremberg, em que os prisioneiros alemães foram julgados, tornou-se uma questão desafiadora por envolver quatro diferentes línguas: alemão, inglês, francês e russo.

Foi nesse contexto que a interpretação simultânea ganhou destaque, a possibilidade de uma interpretação consecutiva foi descartada já que esta modalidade exige uma pausa do locutor do discurso; o intérprete ouve um determinado trecho do discurso, faz anotações e, em seguida, interpreta o discurso. No julgamento de Nuremberg essa modalidade tornaria mais longas as audiências, o que seria inviável também pelo número de línguas envolvidas. Então, a opção foi a interpretação simultânea, que é a modalidade em que a interpretação vai ocorrendo concomitantemente com a produção do discurso. Esta experiência contribuiu para o trabalho da interpretação simultânea que temos atualmente.

Além da interpretação consecutiva e da simultânea, há, também, a forma intermitente, porém as pesquisas a respeito dessa modalidade ainda são muito recentes. Ela é comumente empregada encontrada em reuniões, nas quais solicita-se a um intérprete não profissional (comumente sem prática de tradução), que conheça as duas línguas, que se coloque ao lado da pessoa que vai falar, para, assim, interpretar o que está sendo dito. O orador diz duas ou três frases curtas e espera que a pessoa que está ao seu lado faça a interpretação. Essa modalidade tem foco na interpretação das palavras, e não há preocupação com outras questões relevantes do processo interpretativo (PAGURA, 2003).

A modalidade intermitente pode ser comparada, grosso modo, com situações vividas pelos Codas quando, ainda crianças, faziam as mediações da fala dos pais surdos com familiares 
ouvintes, ou em reuniões com professores na escola e em outros contextos. O Coda, quando criança, e muitas vezes quando adulto, não tem prática em interpretar e desconhece os processos interpretativos. Por desconhecer técnicas tradutórias, o Coda tem como base sua experiência familiar e cultural com as línguas envolvidas, mediando a relação entre a Libras e a Língua Portuguesa.

Ainda que o trabalho de tradução seja antigo, a teorização e o estabelecimento dos estudos da tradução da língua de sinais na academia são recentes. Contudo, abriu-se a possibilidade de discutirmos a atuação do Coda Tradutor-intérprete sob o prisma de um profissional que vivenciou a Língua de Sinais — LS - e a cultura surda de uma forma diferente da maioria dos intérpretes não Codas. Para Campos (1986),

\footnotetext{
Não se traduz afinal de uma língua para outra, e sim de uma cultura para outra; a tradução requer assim, do tradutor qualificado, um repositório de conhecimentos gerais, de cultura geral, que cada profissional irá aos poucos ampliando e aperfeiçoando de acordo com os interesses do setor a que se destine o seu trabalho. (CAMPOS, 1986, p .27 - 28).
}

Ao longo de muito tempo, o conjunto de documentos sobre tradução acessível se fundamentava, basicamente, nas observações de tradutores sobre seus próprios trabalhos, suas impressões, experiências particulares e conselhos sobre a forma mais adequada de traduzir, em uma perspectiva preeminente de orientação (MARTINS, 2010).

No Brasil, seguindo as publicações internacionais, os Estudos da Tradução apontam as diferenças e semelhanças entre a tradução e a interpretação encontradas, por exemplo, em Alves e Pagura (2002) e Pagura (2003). Um dos grandes contrastes utilizados na área para destacar as diferenças dos dois processos é que a tradução trabalha com textos escritos e registros das línguas envolvidas, enquanto a interpretação, com textos orais. Lima (2006, p.35) apresenta como principal diferenciação entre as duas atividades os modos de realização das mesmas: "enquanto o tradutor pode interromper o seu trabalho para consultar fontes internas e externas, o intérprete tem de adquirir todo o vocabulário e o conhecimento necessário antes do ato tradutório em si”.

Traduzir e interpretar vão além de simplesmente conhecer a língua e transpô-la para outra. Não basta saber duas línguas, é necessário vivenciar, experienciar as culturas, e isso vai além da questão linguística. Traduzir e interpretar englobam experiências sociais e culturais, pois para realizar uma tradução ou interpretação é necessária a incursão na cultura do outro, tendo segurança do que está sendo dito/registrado, adequando-o ao emissor e ao receptor. 
Quando conhecemos a cultura do outro, temos mais propriedade para tomar as decisões tradutórias:

\begin{abstract}
Compreendemos que, mesmo diante da importante diferenciação entre tradução e interpretação e seus devidos encaminhamentos práticos para a atuação dos profissionais que a realizam amplamente abordada pelos teóricos da tradução e interpretação, a tradução envolve interpretação e a interpretação envolve tradução, visto que estamos falando de diferentes dimensões da mobilização de discursos (SOBRAL, 2008, p. 225).
\end{abstract}

Assim, traduzir e interpretar a Língua de Sinais - LS - envolve normas, valores sociais e culturais da língua. Caso contrário, o público-alvo, nesse caso os surdos brasileiros, ainda se sentirá estrangeiro em seu próprio país. A tradução e a interpretação devem atingir a língua-alvo, respeitando as características linguísticas e culturais dessa língua (SEGALA, 2010):

Quando o intérprete é tocado pelas fibras mais íntimas da escuta ao outro, ele reconhece sua estrangeiridade e sente-se na posição conflituosa e ambivalente da condição intervalar, com a responsabilidade de negociação de sentidos em zonas de contato, responsabilidade da tradução cultural. (MASUTTI, 2007, p. 100).

Se traduzir e interpretar requerem conhecimento profícuo de cultura, podemos dizer que o intérprete Coda possui uma bagagem cultural extensa que, em muitos casos, contribui para uma tradução e interpretação mais próximas do público surdo, ou seja, uma interpretação mais intimista. A tradução contribui para compreendermos a língua com os recursos que já possuímos e usarmos essa língua para aprimorar nosso conhecimento. Traduzir e interpretar nos permitem ter contato com uma língua diferente, estrangeira, que, ao estabelecermos contato com a diferença, torna-se significativa e instigante, pois através do contato com o outro podemos aprender algo além do linguístico.

Ao não atingir a língua-alvo, conclui-se que a tradução e a interpretação foram construídas e elaboradas de forma fragmentada, ou seja, foram construídas na base linguística da língua fonte. Para o outro compreender o que está sendo dito/interpretado, o contexto tradutório deve estar permeado pela língua-alvo, a língua desse outro.

Para Theodor (1976), tradutores e intérpretes lidam com a língua, trabalham com a língua do outro e com a sua língua originária. São sujeitos que carregam seus processos sociais e históricos, ideias, valores, desejos, marcas que são inerentes ao social, político e econômico. Esses pressupostos estão presentes na concretude do que dizem e/ou fazem. Diante disso, a neutralidade no que é traduzido e interpretado não se faz presente. Essa atividade de traduzir e 
interpretar comporta para o outro significados e sentidos de uma língua em relação à língua de origem.

Assim, a tradução e a interpretação carregam em seu bojo o conteúdo linguístico atrelado ao cultural. Para o Coda tradutor e interprete, o aprendizado de algo além do linguístico foi concomitante ao aprendizado da LS. A experiência visual, assim como a maneira de a pessoa surda se colocar no mundo, permeou o desenvolvimento linguístico e cultural desse profissional.

Bassnett (2005) argumenta que:

É significativo o fato de Homi Bhabha usar o termo "tradução" não para descrever uma transação entre textos e línguas, mas no sentido etimológico de ser carregado de um local a outro. Ele usa tradução metaforicamente para descrever a condição do mundo contemporâneo, onde milhões migram e mudam de local todos os dias. Em um mundo como este, a tradução é fundamental: devemos lembrar que é "intra" - o limite da tradução e da renegociação, o espaço dentre -entre - que carrega o peso do significado da cultura. (BASSNETT, 2005, p. 17).

Ao afirmar que o Coda representa a acessibilidade para os pais, podemos compreender 42 que o espaço dentre-entre citado por Bassnett é o lugar de intermediação ocupado pelo Coda na relação dos pais surdos com o outro, o ouvinte.

De acordo com que pontuou Preston (1995), após ter entrevistado 150 crianças ouvintes e filhas de pais surdos, a experiência de cada entrevistado é singular. Nesse sentido, ler as referências culturais inscritas nas entrevistas torna possível ampliar a percepção do universo de surdos e ouvintes em zonas de contato.

Ainda se tratando das questões linguísticas e culturais que o filho de surdos traz consigo, podemos iniciar uma reflexão sobre a constituição desse sujeito que ora se enxerga parte do mundo ouvinte e ora parte do mundo surdo. Esse sujeito é meio de comunicação de seus pais e amigos e faz a interpretação de maneira natural e inconsciente.

Rodrigues (2013), em sua pesquisa de doutorado, ao analisar a atuação de Codas intérpretes e de intérpretes que não são Codas, argumenta:

Durante a análise qualitativa dos dados, vimos que o fato de os ILS participantes da pesquisa serem experientes e, portanto, possuírem uma apurada competência interpretativa intermodal fez com que o fato de ser ou não CODA tivesse menos ou nenhuma relevância na distinção entre os dois grupos. Nesse sentido, é possível afirmar que tanto CODAs quanto não CODAs precisam adquirir e desenvolver competência tradutória e/ ou competência interpretativa no par linguístico PortuguêsLibras, eliminando quaisquer diferenças iniciais relacionadas ao fato de serem ou não nativos nas línguas envolvidas na interpretação e, portanto, lidando habilmente com 
os efeitos de modalidade sobre o processo de interpretação. (RODRIGUES, 2013, p. 226).

Compreendemos que o desenvolvimento da competência tradutória e/ou competência interpretativa deve permear a busca por profissionalização do Coda intérprete. Contudo, o convívio com os artefatos culturais do surdo, desde a infância, permite a ele lançar mão desses elementos durante o ato tradutório-interpretativo.

Segundo Souza (2014), os Codas realizam com seus pais o "language broker": “categoria de mediadores bilíngues (diferentemente da interpretação realizada por intérpretes com formação específica)" (SOUZA, 2014, p. 44). Essa mediação linguística é possível devido ao fato de os Codas estarem aculturados na comunidade surda, que se comunica através de uma língua visual e espacial.

Sendo assim, essa aculturalização acontece de maneira natural e automática. Os textos analisados nesse estudo nos mostram um pouco disso, os quais apresentaremos na próxima seção.

\section{O lugar que o Coda Tradutor-intérprete ocupa na área da tradução e interpretação do par linguístico Libras-Língua Portuguesa}

Uma revisão de literatura é necessária para representar o campo temático, no nosso caso os Codas e a tradução e interpretação de Libras-Língua Portuguesa. Nesse trabalho, seguimos uma metodologia sistemática em busca de uma representação do campo (STAKE, 2011).

Apresentaremos, a seguir, uma leitura analítica dos trabalhos acadêmicos que abordam a temática dos CTILS indiretamente, fazendo um levantamento dos aspectos culturais presentes nesses trabalhos que contribuem para a melhor compreensão do lugar que o Coda Tradutorintérprete ocupa na área da tradução e interpretação do par linguístico Libras-Língua Portuguesa.

Os trabalhos acadêmicos selecionados foram:

- "Codas brasileiros: libras e português em zonas de contato", de Ronice Müller de Quadros e Mara Massutti (2007);

- "Identidades de filhos Ouvintes quando os pais são surdos: uma abordagem sociológica sobre o processo de socialização”, de Pablo Regis Andrade (2011);

- "Nascidos no silêncio: as relações entre filhos ouvintes e pais surdos na educação", de Osmar Roberto Pereira (2013); 
- “CODA: um mundo, duas culturas? Dois mundos, duas culturas?”, de Sônia Marta de Oliveira (2014);

- "INTÉRPRETES CODAS: construção de identidades", de José Carlos Ferreira Souza (2014).

Iniciamos com o trabalho de Quadros e Massutti (2007), que aborda as zonas de contato e o entrelugar em que se situam as vidas dos Codas, pois, devido às línguas e culturas que ora se cruzam, ora se distanciam, esses apresentavam uma experiência singular de perceber e participar do mundo ao seu redor. O artigo discute as relações que se estabelecem entre a Língua de Sinais e a Língua Portuguesa no Brasil, trazendo reflexões sobre os aspectos que envolvem situações de fronteira e contato entre línguas, bem como as percepções do universo surdo e daquele do ouvinte, destacando as formas como as conexões são percebidas por este Coda.

$\mathrm{O}$ artigo situa o leitor frente à realidade do bilinguismo no Brasil e à Língua Brasileira de Sinais para, em seguida, abordar a análise das zonas de contato e fronteiras estabelecidas por meio de elementos linguísticos, culturais e políticos que constroem as diferentes perspectivas de um Coda. Conforme as autoras:

A experiência de nascer, viver e crescer em meio a uma família de pais surdos faz com que a percepção das representações culturais, sociais, políticas e linguísticas sejam atravessadas por substratos filosóficos, éticos e estéticos marcados por tensões em zonas fronteiriças de contato. O universo surdo e ouvinte marcam as fronteiras dos Codas. (QUADROS; MASUTTI, 2007, p. 246).

Nesse texto é apresentado um resgate histórico em relação à Libras e aos surdos. Durante muito tempo as escolas de surdos e as classes especiais não permitiam o uso da Língua de Sinais, privilegiando o uso da Língua Portuguesa, reforçando uma hierarquia entre as línguas baseada na premissa de superioridade das línguas orais, o que influenciava a vida dos surdos e, consequentemente, a vida de seus filhos.

Os surdos da década de 60, juntamente com seus filhos Codas, vivenciaram muitas histórias, dentre elas os processos de negação da LS. A maioria desses surdos tiveram contato com a Língua de Sinais nas associações de surdos, onde exercitavam sua língua e cultura. Mesmo com a proibição e a hierarquia entre as línguas, nas décadas de 80 e 90 algumas mudanças aconteceram: as associações passam a ser espaços políticos de discussão e luta por direitos e algumas escolas começam a fazer uso da Língua de Sinais.

Esse levantamento do contexto de vida de surdos e Codas apresentado pelas autoras possibilita-nos compreender e problematizar questões relacionadas ao reconhecimento da 
Libras no Brasil. Todo esse movimento político influenciou no modo como a Libras passou a ser vista, pois quando começou a ser introduzida nas escolas e nos espaços universitários, os surdos passaram a ter intérpretes em sala de aula. Além disso, tratando-se de meados de 2000, um período favorável às políticas linguísticas afirmativas, conquistou-se o reconhecimento legal da Libras como língua.

Andrade (2011), em sua dissertação de Mestrado na área de Sociologia, da Universidade Federal de Goiás, reflete sobre as identidades de filhos ouvintes quando os pais são surdos, trazendo uma abordagem sociológica sobre o processo de socialização, tendo como base teórica os Estudos Culturais, a Teoria Relacional de Pierre Bourdieu e o "Estigma da Cortesia", de Erving Goffman. Como aporte metodológico, realizou entrevistas com familiares dos surdos baseadas em "memórias" e, além disso, uma revisão literária, obtendo os seguintes tópicos: diferentes visões do que é ser surdo, identidades de fronteira "entre" e "ganho linguístico" com relação aos não Codas.

Com isso, durante sua reflexão, o autor afirma que o fato de os filhos de pais surdos terem adquirido duas línguas, desde tenra idade, faz necessária a responsabilidade de interpretação desde a infância. Afinal de contas, a criança que está entre o mundo ouvinte e o mundo surdo seria o elo entre os pais e o mundo externo.

O autor dá início a uma investigação para compreender a construção das identidades de ouvintes, filhos de pais surdos, como se identificam e como são identificados pelo mundo, problematizando primeiramente o conceito de família para, logo em seguida, fazer um breve resgate de como se constitui a sigla CODA nos EUA. Andrade chama a atenção ao dizer que, no Brasil, fora feita uma breve busca por algo que envolvesse filhos de pais surdos, e nada foi encontrado. Vale ressaltar que a conclusão dessa pesquisa ocorreu no ano de 2011, dois anos antes do primeiro encontro nacional de Codas Brasileiros.

Somado a isso, Andrade realizou um resgate de textos que tratavam da surdez e de filhos ouvintes de pais surdos, constatando que esses textos tinham como objeto o próprio indivíduo surdo e reafirmando que produções a respeito de Codas são escassas. O achado foi de textos que discutiam a surdez contada na perspectiva do ouvinte e recontada por surdos em defesa da cultura surda:

\footnotetext{
A identidade social que o filho recebe passa a conter elementos que fazem parte da representação sobre os pais. Em certo sentido, existe não somente um compartilhamento de valores sociais e morais, mas do significado de "não normal"que os surdos receberam. Contudo, essa condição nem sempre resulta em algum conflito entre pais e filhos, pois, para utilizarmos um conceito presente em França (2008),
} 
enquanto membros da família, os filhos são capazes de se colocar no lugar daqueles com quem se relacionam a fim de experimentarem a lealdade como condição prática. (ANDRADE, 2011, p. 42).

Além de fazer um breve resgate a respeito da cultura surda, Andrade (2011) expõe uma comparação entre os surdos e os imigrantes que vivem fora de seus países, pois passam por situações similares aos da comunidade surda. Porém, é importante lembrar que os surdos acabam sendo imigrantes em seu país, diferentemente dos imigrantes estrangeiros, que só passam pela mesma situação, caso seus filhos se tornem seus intérpretes, quando estão fora do país onde nasceram. Além disso, é mais fácil o acesso à língua no país imigrante pelos filhos, pois essas crianças chegam e frequentam espaços escolares, adquirindo a língua mais rapidamente que os pais.

O autor, não sendo Coda, traz relatos de um americano chamado Bull, que coloca o quanto é estranho ter de se nomear "ouvinte" e quantas vezes se sentiu só, sem que outros pudessem dividir experiências semelhantes com ele, já que não havia uma empatia direta. No Brasil, a existência de encontros de Codas nos permite uma oportunidade de socialização de 46 experiências e sentimentos de um grupo que estáà margem da maioria. Essa é uma das possibilidades que os encontros oferecem aos que participam: eles passam a conhecer e se reconhecer com e no outro, o que também permite dividir suas experiências pessoais e profissionais com seus semelhantes.

Pereira (2013) fala um pouco, na sua dissertação "Nascidos no Silêncio: As relações entre filhos ouvintes e pais surdos na educação", sobre as relações estabelecidas entre filhos e pais, tendo por base teórica a Educação de Surdos, a Antropologia e a Autobiografia. A pesquisa foi realizada de forma literária e produziu uma análise dos depoimentos colhidos em entrevistas de pais surdos e filhos ouvintes, chegando à conclusão de que ser filho de pais surdos pode ser tão normal quanto ser filho de pais ouvintes.

A dissertação de Pereira faz com que se reflita sobre o quanto está impregnada socialmente a visão da incapacidade daqueles que são considerados "não normais"; o quanto esse tipo de preconceito interfere não apenas na vida social, mas também pessoal das pessoas surdas, pois nos é relatado, na referida pesquisa, que por causa desse preconceito muitas famílias de surdos foram impedidas de ter ou de criar seus próprios filhos.

Além da falta de credibilidade direcionada aos pais surdos, também se revela certo receio de como seria a vida dessa criança Coda junto a uma sociedade tão estigmatizadora. Quando a família é extensa, ou seja, com avós, tios e demais familiares dos surdos, muitas vezes 
esses impedem os pais surdos de criarem seus filhos sem que exista a presença de alguém ouvinte por perto. Com isso, percebe-se nítida proteção e medo de que algo de ruim aconteça com essa criança.

A justificativa dada para que isso ocorra é a falta de audição dos pais, pois, logo que o Coda cresce, a responsabilidade pelos pais é transferida a ele. Entretanto, as três famílias entrevistadas deixaram claro que é, sim, normal uma criança ouvinte ser criada por pais surdos, mas existem alguns aspectos que os tornam diferentes dos ouvintes:

Olhando para trás, em minha trajetória formativa é interessante notar que o maior medo da minha família ouvinte era de que ter os pais surdos seria prejudicial para o meu desenvolvimento e que isso poderia acarretar em um atraso no meu aprendizado de fala e por consequência no processo de alfabetização, mas a vida nos prega peças. Hoje estou aqui, professor universitário e intérprete de LIBRAS, concluinte de um programa de Mestrado em Educação, podendo mostrar para a sociedade que o surdo não está limitado por não ouvir e que ele pode ser um bom pai, uma boa mãe, um bom profissional e ser protagonista de sua própria vida. Outro ponto positivo é que, como pesquisador, especificamente neste trabalho, pude observar de "dentro" a trajetória que os Codas percorrem dentro das famílias nas quais estão inseridos. Afinal, também sou sujeito de minha própria pesquisa. (PEREIRA, 2013, p. 27).

Um dos fatores citados nas análises é o fato de o filho se tornar responsável pelos pais antes do tempo, tendo acesso a informações que outras crianças não têm. Algumas práticas solicitadas a essas crianças, por exemplo, seriam assistir ao Jornal Nacional e interpretar o que está sendo dito a respeito da política atual ou acompanhar os pais ao médico. Crianças ouvintes não realizam esse tipo de atividade, a não ser que sejam crianças filhas de imigrantes que também se tornam intérpretes de seus pais.

Dos três entrevistados, além do autor, que é Coda, somam-se quatro participantes, sendo que três deles, depois de adultos, tornaram-se profissionais intérpretes e viram isso como uma "sorte". Afinal de contas as experiências em sua tenra idade serviram, na vida adulta, como "ganha pão". Uma profissão herdada pela singular experiência de serem filhos de pais surdos.

O trabalho de Pereira (2013) traz um breve histórico de como eram vistos os casais surdos quando decidiam formar uma família e ter filhos. Atualmente não nos parece muito diferente, mas, como dito pelo autor, hoje em dia a comunidade surda já tem seus direitos e leis garantidos. Ainda assim, esses direitos não foram plenamente implementados, como é o caso da garantia ao acesso à Língua de Sinais em hospitais, clínicas e bancos, entre outros espaços.

A falta de acessibilidade explicitada anteriormente é um dos motivos que refletem nos filhos de pais surdos, fazendo-os passar pela experiência de serem intérpretes desde a infância. Como também mencionado pelo autor, essas crianças não realizam interpretações somente em 
locais públicos, mas também dentro de suas casas, pois os próprios avós, por vezes, precisam delas para comunicar algo, nesse caso, aos seus filhos, ou até mesmo para intermediar telefonemas dentro de suas próprias casas.

Atualmente, com a evolução da tecnologia e o direito de estudar diretamente em sua primeira língua, muitos surdos já não levarão seus filhos aos espaços como os citados anteriormente para serem os mediadores. Porém, não podemos nunca afirmar que para todos os Codas isso acontecerá, já que as realidades são diferentes.

O objetivo de Pereira é mostrar o quanto os surdos são capazes de criar e organizar suas famílias, possibilitando que os familiares dos surdos possam confiar neles enquanto chefes de família, sem interferir no processo de construção e constituição familiar. Além disso, as crianças filhas de pais surdos querem e precisam ser criadas pelos próprios pais, mesmo que isso implique diferentes experiências e aprendizados.

Oliveira (2014), em seu relato de experiência intitulado "Coda: um mundo, duas culturas? Dois mundos, duas culturas?", apresenta uma pesquisa qualitativa com dez entrevistados Codas, tendo como base teórica os Estudos Culturais. Tal pesquisa, que ainda está 48 em andamento, reflete que ser Coda não é melhor nem pior que ser filho de pais ouvintes. Ser Coda é ter uma nova perspectiva sobre a diferença.

Oliveira relata uma maneira diferenciada de ser Coda, pois, ao contrário de Pereira (2013) e seus sujeitos de pesquisa, ela não interpretava para os pais durante a infância, uma vez que os pais preservavam a ela e aos seus irmãos. Assim, por exemplo, o acesso a televisão era algo com horários e programas restritos, pois os pais não sabiam se aquele conteúdo seria adequado às crianças, permitindo que eles somente assistissem aos desenhos que eram para suas respectivas faixas etárias. A autora lembra que, aos 14 anos, começou a interpretar para seus pais; conta também que a visão que era passada a ela sobre a surdez era a mais positiva possível, pois seus pais faziam com que ela tivesse orgulho de ter acesso às duas línguas, duas culturas, uma visão em que a diferença estava marcada culturalmente como uma colcha de retalhos em que as histórias se entrecruzavam no melhor dos sentidos.

Uma criança ouvinte filha de pais surdos é geralmente exposta primeiramente à língua de sinais. Considero importante salientar que cada história de vida é única. Minha experiência com meus pais surdos e familiares surdos não deve ser tomada como referência. Somos todos únicos e ao mesmo tempo um mosaico de "outros" com os quais convivemos. (OLIVEIRA, 2014, p.278). 
Porém, a história não difere muito da de outros Codas que, ao chegarem à escola, começam a perceber novos olhares para a surdez, quando o olhar etnocêntrico prevalece, e é nesse momento e espaço que aprendem e sentem o olhar de julgamento do outro com relação a sua família. É no meio social e escolar que este preconceito surge.

No entanto, o relato de Oliveira nos traz muitas questões relacionadas à cultura surda, seu aprendizado visual, seu convívio com a associação de surdos, enfatizando o quanto é importante e essencial imergir nessa comunidade específica para conhecer o outro, ou seja, ter um olhar de alteridade frente a um povo que tem uma cultura ímpar.

Diante do que é posto por Oliveira, talvez esteja na imersão o diferencial de ser Coda, pois vivemos e experienciamos, dentro do cotidiano e em situações relacionadas à comunidade surda, a falta de comunicação; o conhecer o mundo com os olhos, e não com os ouvidos; as crenças geradas a partir das diferenças e estigmas impostos pela sociedade majoritária, que acredita em um país monolíngue e em pessoas normais; a realidade vivida por um grupo que é minoria, mas é forte e vem demonstrando o quanto sua cultura e língua têm poder e merecem respeito.

Souza (2014), em sua dissertação nos Estudos da Tradução, buscou compreender como se estabelece o perfil profissional do Coda enquanto Tradutor-intérprete de Libras, pressupondo que as motivações culturais vividas por esses sujeitos trazem desdobramentos para o perfil profissional. Sua pesquisa é intitulada "Intérpretes Codas: Construção de identidades", tendo como fundamentação teórica a interpretação comunitária, os estudos históricos, cognitivos, comportamentais, linguísticos, sociais, éticos e a prática interpretativa. Somado a isso, propôs um trabalho metodológico de caráter qualitativo, que utilizou entrevistas semiestruturadas e um grupo focal, resultando em indícios das marcas culturais surdas que advêm das experiências familiares, identidades múltiplas e fragmentadas.

Tal pesquisa apresenta o Coda de maneira geral, contextualizando o surgimento da sigla, bem como o porquê e onde iniciou esse movimento fora e dentro do Brasil. Souza trata de uma forma muito peculiar a maneira de representar o sujeito Coda, fazendo uso metafórico do "encontro das águas", entre o rio Negro e o Solimões, com o ser Coda em contato com a comunidade surda e a ouvinte. É uma mistura que ocorre naturalmente entre culturas e identidades; é uma experiência como filho de pais surdos em meio a esta "mistura", trazendo para a reflexão autores como Preston (1995), Abrams (1996) e Davis (2001). 
As reflexões sobre as possibilidades identitárias de Codas intérpretes de Língua de Sinais são abordadas na pesquisa, pois eles carregam experiências junto à comunidade surda, acarretando, assim, a possibilidade de uma influência identitária profissional nesses sujeitos:

O filho de surdos pode crescer vivenciando a princípio os artefatos culturais como: experiência visual, linguística, familiar, literatura surda, vida social e esportiva, artes visuais, políticas e materiais. Porém o Coda vivencia todos estes processos com audição, o que pode trazer outras questões a respeito de identidade. (SOUZA, 2015, p. 27).

Tendo em vista que o trabalho trata acerca das identidades, Souza reflete sobre as múltiplas identidades (HALL, 2006) e sobre o perfil do sujeito marcado por uma identidade fragmentada e com experiências empíricas diferentes das ensinadas formalmente em cursos de formação e diferentes daquelas vividas por irmãos, tios ou parentes de surdos. Além disso, o texto nos mostra que existe uma negociação constante por parte do Coda ao se deparar com o significado dos dois mundos, surdo e ouvinte, bem como uma distinção não definida entre ser filho e ser intérprete, o que, por vezes, acarreta problemas emocionais.

50 Diante desses trabalhos, construí o mapa a seguir (Figura 1), que apresenta uma descrição ilustrativa sobre os assuntos e temas presentes nos trabalhos acadêmicos analisados. O mapa pode auxiliar na visualização das temáticas e uma síntese da análise que realizei anteriormente.

Figura 1 - Mapa

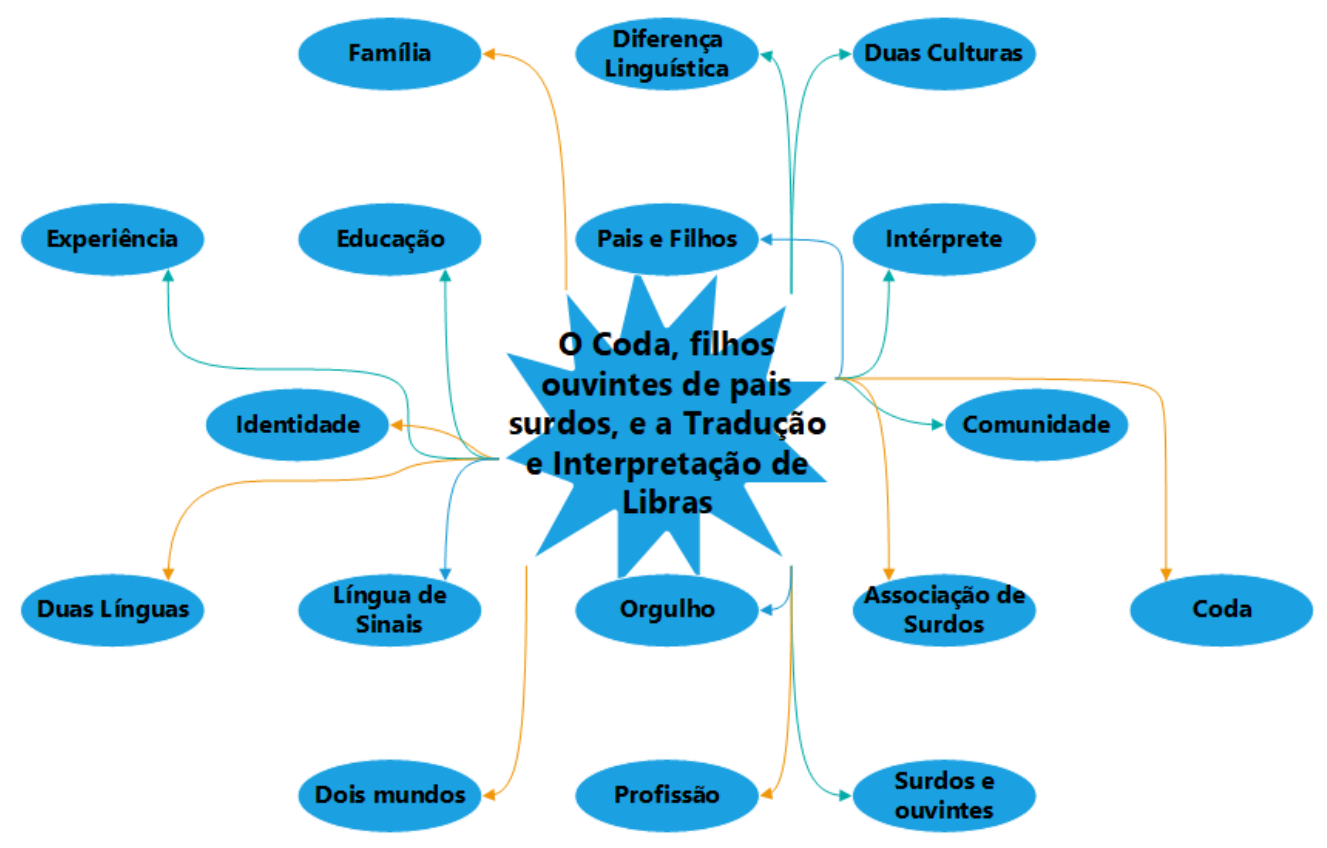

Fonte: Maitê Maus da Silva 


\section{Considerações finais}

Com base nas leituras e reflexões dos textos que apresentam o olhar e o lugar de onde vem o Coda e suas experiências de vida entre duas línguas e duas culturas; a relação com os pais, familiares surdos e ouvintes; seu desenvolvimento entre dois mundos; a relação destas famílias constituídas por pais surdos e crianças ouvintes; a exposição, para a sociedade, de uma diversidade que, para a criança Coda, é algo tão natural. Aos olhos do outro, ouvinte, a diversidade surda foge ao padrão de normalidade. Por terem uma língua e uma cultura diferentes, os surdos são vistos somente pela falta de algo, nesse caso, a audição. Não há um olhar voltado à diferença linguística e cultural que possuem. Assim, ser Coda é crescer em meio a essa dita diferença, é viver em um contexto visual e linguístico que não é vivenciado por crianças ouvintes, filhas de pais ouvintes.

As experiências de interpretação dos Codas influenciam na sua constituição enquanto pessoas e, ainda mais, como profissionais da área da tradução e interpretação do par linguístico Libras/Português. Considerar a fronteira, suas relações, proximidades e familiarização com a Língua de Sinais e com a cultura surda, assim como os processos de constituição identitária e os de registro histórico, demonstra-nos o quanto o tempo e o ambiente são imprescindíveis e não devem ser ignorados.

Produções como as que foram apresentadas nesse estudo estão em constante crescimento no meio acadêmico, contribuindo para o fortalecimento da profissão e para o enriquecimento das pesquisas nessa área de concentração. Agregados a esses pressupostos poderemos fortalecer a profissão e fazer com que a comunidade compreenda que crianças Codas podem ser facilitadoras e mediadoras da comunicação entre seus pais surdos e as pessoas ouvintes. Contudo, hoje temos profissionais qualificados, formados para exercer com proficiência a função de tradutor intérprete, cooperando para que a tradução e a interpretação da Língua de Sinais passe a ser valorizada e reconhecida para além da educação, como uma área de investigação e profissionalização.

\section{REFERÊNCIAS BIBLIOGRÁFICAS}

ABRAMS, C. The Silents. Washington, DC: Gallaudet University Press, 1996.

ANDRADE, P. Regis. Identidades de filhos ouvintes quando os pais são surdos: uma abordagem sociológica sobre o processo de socialização. 2011. 129f. Dissertação (Mestrado em Ciências Humanas) - Universidade Federal de Goiás, Goiânia, 2011. 
BASSNETT, Susan. Estudos da tradução. Trad. Sônia Terezinha Gehring, Leticia Vasconcellos Abreu, Paula Azambuja Rossato Antinolfi. Porto Alegre: Editora da UFRGS, 2005.

CAMPOS, Geir. O que é tradução. São Paulo: Brasiliense, 1986. (Coleção Primeiros Passos).

DAVIS, L. My Sense of Silence: Memoirs of a childhood with deafness. Urbana: Universityof Illinois Press,2001.

HALL, Stuart. A identidade cultural na pós-modernidade. Tupy Kurumin, 2006.

LIMA, S. Elcivanni. Discurso e Identidade: Um olhar crítico sobre a atuação do(a) intérprete de Libras na educação superior.Dissertação, (Mestrado em Linguística) Programa de Pós graduação Linguística da Universidade Federal de Brasília, Brasília (2006).

MASUTTI, Mara Lúcia. Tradução cultural: desconstruções logofonocêntricas em zonas de contato entre surdos e ouvintes. 2007. 165f. Tese (Doutorado em Literatura) - Centro de Comunicação e Expressão, Universidade Federal de Santa Catarina, Florianópolis, 2007.

OLIVEIRA, Sonia Marta de. CODA: Um mundo, duas culturas? Dois mundos, duas 52 culturas? In: QUADROS, Ronice Muller de; WEININGER, Markus J. Estudos da Língua Brasileira de Sinais. Florianópolis: Insular, 2014. Cap. 12. p. 277-286. (Volume III).

PAGURA, Reynaldo. A interpretação de conferências: Interfaces com a Tradução Escrita e Implicações para a Formação de Intérpretes e Tradutores. DELTA, 19: Especial. 2003, p. 203- 236. Disponível em:

http://www.scielo.br/scielo.php?script=sci_arttext\&pid=S0102-44502003000300002. Acesso em: 10 jun. 2016.

PEREIRA, Osmar Roberto. Nascidos no Silêncio: As relações entre fillhos ouvintes e pais surdos na Educação. 2013. Dissertação (Mestrado em Educação) - Universidade Metodista de São Paulo, São Bernardo do Campo, 2013.

PERLIN, Gladis Teresinha Taschetto. O ser e o estar sendo surdos: alteridade, diferença e identidade. 2003.Tese de Doutorado, Programa de Pós-Graduação em Educação, Universidade Federal do Rio Grande do Sul, Porto Alegre. 2003

PRESTON, Paul. Mother father deaf: living between sound and silence. First Harvard University Press, 1995.

QUADROS, R. M. de; MASUTTI, M. L. Codas brasileiros: Libras e português em zonas de contato. In: Estudos Surdos II. Petrópolis: Rio de Janeiro,2007.

RODRIGUES, Carlos Henrique. A interpretação para a Língua de Sinais Brasileira: efeitos de modalidade e processos inferenciais. 2013. Tese de Doutorado, Programa de PósGraduação em Estudos da Tradução, Universidade Federal de Santa Catarina, Florianópolis. 2013. 
SEGALA, Rimar Ramalho. Tradução intermodal e intersemiótica/interlingual: português brasileiro escrito para Língua Brasileira de Sinais. 2010. Dissertação (Mestrado em Tradução) - Centro de Comunicação e Expressão, Universidade Federal de Santa Catarina, Florianópolis, 2010.

SILVA, Maitê Maus. Codas tradutores e intérpretes de língua de sinais brasileira: percurso para o profissionalismo. 2016._Dissertação (Mestrado em Tradução) - Centro de Comunicação e Expressão, Universidade Federal de Santa Catarina, Florianópolis, 2016.

SOBRAL, Adail. Posfácio. In: BENEDETTI, Ivone C. \& SOBRAL, Adail (Org.) Conversas com tradutores: balanços e perspectivas da tradução. São Paulo: Parábola, 2008, pp. 201214.

SOUZA, José Carlos F. INTÉRPRETES CODAS: Construção de identidades. 2014. Dissertação (Mestrado em Tradução) - Centro de Comunicação e Expressão, Universidade Federal de Santa Catarina, Florianópolis, 2014.

SOUZA, José Carlos F. Intérpretes Codas: Language Brokering e a Profissão de Intérprete de Libras. Anais do V Congresso de Tradução e interpretação das Línguas de Sinais, UFSC, Florianópolis, 2014.

STAKE, Robert E. Pesquisa qualitativa: Estudando como as coisas funcionam. Tradução: Karla Reis.Porto Alegre: Penso, 2011.

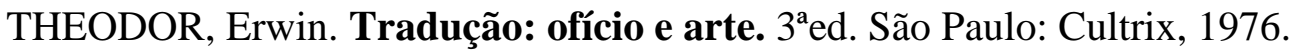

\footnotetext{
${ }^{\text {i }}$ Maitê Maus da SILVA - Mestre em Estudos da Tradução (2016) e graduada em Letras/Libras (2012) pela Universidade Federal de Santa Catarina. É tradutora e intérprete de Língua Brasileira de Sinais da Universidade Federal de Pelotas. Pelotas, Rio Grande do Sul, Brasil. ORCID:

Lattes: http://lattes.cnpq.br/6844464824549394 E-mail: maitetils@gmail.com

${ }^{1}$ Fonte: https://www.coda-international.org/

${ }^{2} \mathrm{~A}$ comunidade surda é um aspecto mais híbrido na constituição epistêmica, como um grupo instável de pessoas que o constitui. Tanto podem ser os surdos, os ouvintes filhos de pais surdos, os intérpretes e os que sinalizam com os surdos. (PERLIN, 2003, p.20).
} 